Departamento de Anatomia Patológica

Diretor Prof. Dr. Altino A. A. Antunes

\title{
RABDOMIOMA NO CORAÇÃO DE UM BOVINO $\left({ }^{*}\right)$
}

\author{
POR \\ Rubens Escobar Pires, Assistente \\ e \\ Paschoal Mucciolo, Ex-Assistente \\ Com 6 estampas
}

Por circunstâncias ainda não bem conhecidas, o coração é pouco sujeito às neoplasías, quér sejam primárias (derivadas dos componentes próprios do órgão), quér secundárias (metástases de tumores assestados em outros órgãos).

Não cabe, dentro de uma comunicação como esta, o estudo aprofundado das cáusas de tal particularidade, pois, seria penetrar na essência íntima da oncogênese, assunto bastante estudado e ainda obscuro.

No grupo dos tumores primários do coração, o rabdomioma, isto é, o tumor originado da musculatura estriada, é um dos mais raros, embóra abrangendo aquêles denominados de «Rabdomioma congênito do coração» sôbre o qual, como veremos mais tarde, ha opiniões divergentes quanto à sua significação.

O rabdomioma, mesmo fóra da localização cardíaca, é tumor raro podendo aparecer em todo lugar onde haja musculatura estriada ou mesmo onde falta, correndo então provavelmente por conta de réstos embrionários que aí permaneceram incluidos.

Quanto à sua fórma, pódem ser simples ou múltiplos, nodulares ou volumosos, chatos ou arredondados, circunscritos ou difusos e, às vezes, polipóides.

Ao córte, apresenta-se frequentemente de consistência móle e de superfície acinzentada, havendo bastante tecido fibroso delimitando campos tumorais. As fórmas muito celulares são bastante móles e difusas e a coloração se tórna amarelada ou vermelha.

O rabdomioma póde aparecer tambem em tumores mixtos, constituindo, nessa apresentação, um verdadeiro teratôma.

A estrutura microscópica dos rabdomiomas apresenta elevado gráu de polimorfismo. Alguns são constituidos quasi inteiramente por células fusifórmes semelhantes ao mioblasto indiferenciado, às vezes em sincicio, não possuindo fibrilas estriadas e podendo formar células gi- 
gantes pólinucleadas. Outros já apresentam, no protoplasma celular, a formação de fibrilas longitudinais ou transversáis. Outros ainda apresentam as suas células tão parecidas com as células musculares adultas das quais se diferencíam sómente por um ligeiro gráu de anaplasía. Em alguns rabdomiomas foi verificada a presença de tubos cujas parêdes possuiam fibrilas estriadas e, na luz, células fusifórmes com bastante plasma. As células do rabdomioma pódem apresentar, no seu protoplasma, vácuolos grandes, assumindo assim um aspecto de aranha. Esses vácuolos costumam estar cheios de glicogênio e de gordura.

Ha vários típos clínicos de rabdomioma com particularidades próprias segundo os órgãos onde se formam.

Quanto ao seu comportamento, ha os benígnos, crescendo lentamente, sem infiltrar os tecidos vizinhos, nem trazendo maiores dânos ao organismo em geral e os altamente malignos, de caráter infiltrativo acentuado, com crescimento rápido e recidivas fáceis.

Esses atributos não constitúem apanágio dêste ou daquele típo de rabdomioma, pois, póde-se encontrar rabdomiomas do típo de mioblastos indiferenciados com caracteres de benignidade ou de malignidade, o mesmo acontecendo com os outros típos.

$\mathrm{Na}$ literatura veterinária, conseguimos verificar a existencia de poucos casos de rabdomioma do coração e, pelas caracteristicas apresentadas, passamos a descrever mais pormenorisadamente.

O caso de BousEK, foi relatado em 1906, como sendo um adeno-rabdomioma do coração de uma vaca e o quadro histológico era o seguinte: Tratava-se de nódulos do tamanho de uma ervilha, localizando-se no músculo cardíaco. Estava apenas aderente às partes vizinhas e foi possivel retirá-lo com facilidade. As partes vizinhas, mesmo pelo exame microscópico, não apresentavam alterações. O tumor era constituido por zonas alongadas de tecido muscular e conjuntivo em formações concêntricas, de 1,5 cms. de largura, isoladas dos feixes musculares. Nas partes centrais, havia predominância dos feixes musculares, acontecendo o contrário nas partes periféricas, onde prevalecia o tecido conjuntivo. As imagens adenomatósas estavam disseminadas em todos os córtes. As fibras musculares tinham a espessura e comprimento normais, estando algumas dilatadas perto dos núcleos, assemelhando-se às contas de um rosário. O sarcoplasma não poude ser visto com segurança e seus núcleos pareciam com os dos músculos, porém maiores. Em córtes transversáis, os «tubos» eram apenas reconhecíveis e só naquêles cuja fórma estava alterada, havia ausência das faixas transversáis. Estas eram pouco evidentes. As imagens adenomatósas eram em alguns pontos acinosas, noutros, tubulares, revestidas de um epitélio cúbico simples e nada contendo em seu interior. BOUSEK 
classificou esse tecido heterotópico, como um teratôma originado de inclusões fetais.

Hyeronimy e Kukla, em 1921, comunicaram um caso, cuja descrição tanto macroscópica como microscópica se enquadrava no grupo dos rabdomiomas congênitos do coração. O tumor consistia de diversos nódulos espalhados pelo coração, em um suino do sexo feminino, de três mêses de idade, ocasionando a morte. Pelo exame histológico, verificou-se tratar de um típo de tecido cuja descrição e interpretação foi feita pelos autôres da seguinte maneira: «As fibras do rabdomioma são formadas por tubos fibrilares que, em córte transversal, são maiores que as fibras do miocárdio normal. A luz do tubo está cheia de fibrilas estriadas transversalmente e, frequentemente, ha apenas uma camada envolvente e uma parte protoplasmática. O sarcoplasma é granuloso $\mathrm{e}$, às vezes, estriado longitudinalmente, quasi sempre substituido por lacunas e vácuolos, contendo, em muitos casos, glicogênio. Na luz dos tubos, encontram-se frequentemente células fusifórmes com bastante protoplasma, parecendo células ganglionares. O protoplasma marginal é escuro, em fórma de favos e o núcleo claro. O protoplasma dessas células tinha estriação transversal. A parte correspondente ao centro do tumor não apresentava mitóses, porém, em outras zonas, notavamse raras mitóses. A gordura, encontrada por alguns pesquisadores, nos tubos fibrilares, não foi verificada no presente caso. As células fusifórmes enviavam anastomóses polimorfas pelo tubo fibrilar. Algumas estrias transversáis, no seu todo ou em parte, se tinham transformado na substância envolvente fibrilar. Esta continha tambem núcleos alongados e os córtes transversáis, no tecido do rabdomioma, apresentavam estruturas semelhantes a ninhos. Nos laços das malhas foram encontradas células fusifórmes. No miocardio havia nódulos menores, semelhantes ao nódulo maior do rabdomioma».

Courteau cita, em seu trabalho, um caso de rabdomioma do coração de uma vaca, descrito por MAGNisson e do qual não conseguimos mais informações.

Na literatura médica, foi verificada a presença de 45 casos de rabdomiomas do coração, começando pelo de VON RECKLINGHAUSEN, em 1863. Na época anterior ao microscópio, ha descrição de um rabdomioma do coração feita por BILLARD, em 1828, não havendo dúvida quanto à sua significação.

Após os trabalhos de Carrel e Ebeling, com culturas «in vitro» de miocárdio de embrião de galinha, seguidos dos trabalhos de Otivo, LEVI, LEWIS e outros, foram obtidos mioblastos, cuja estrutura seguia, nos vários transplantes, uma espécie de regressão ou melhor, uma des- 
diferenciação, conseguindo-se obter um típo semelhante ao mioblasto indiferenciado do embrião de galinha. Poude-se assim comparar esses resultados, com os dados fornecidos pela histologia dos rabdomiomas e estabelecer a relação entre o mioblasto e a célula blastomatósa em todas suas fáses de evolução.

Aproveitando-se desses resultados, ABricossof que, de longa data, vinha estudando os miomas em geral, apresentou uma classificação mais precisa dos rabdomiomas e a partir dos seus trabalhos de 1926 e 1931 sôbre o assunto, esses tumores foram classificados do seguinte módo:

1.0 - Tumores compostos de mioblastos completamente desprovidos de estriação (Mioblastômas puros).

2.0 - Tumores com mioblastos semelhantes aos primeiros, mas, com estriação longitudinal ou transversal ou ambas, porém, apresentando, frequentemente, um desenvolvimento imperfeito na periferia das células.

3. ${ }^{\circ}$ - Tumores com mioblastos hipertróficos, incluindo alguns de grande tamanho (40-160 micra), frequentemente multinucleados e do típo sincicial. A estriação está presente em alguns, especialmente na zona periférica do citoplasma e está ausente em muitos.

4..$^{\circ}$ - Sarcoma mioblastico atípico. Tumor de celulas polimorfas em algumas áreas, francamente sarcomatoso e, em outras, apresentando maior diferenciação das células, com estriação bem definida longitudinal e transversal.

Mais recentemente, CAPPel e Montgomery (1937) apresentaram uma classificação mais simples. E' a seguinte a sua classificação:

1. ${ }^{\circ}$ - Tumores cujas células apresentam estriação transversal bem definida.

a) Rabdomioma simples, formado totalmente de fibras musculares bem diferenciadas e sem fórmas anaplásticas e primitivas.

b) Rabdomioma maligno ou rabdomioma sarcomatóide, sarcoma pleiomorfo, de células redondas e fusifórmes, apresentando estriação transversal bem definida, ao menos num pequeno número de células. blastômas).

2.0 - Tumores cujas células não apresentam estriação (Mio-

Atualmente as classificações tendem para a simplicidade da de Cappel e Montgomery.

No coração, os rabdomiomas pódem aparecer sob todos os aspectos acima descritos, dêsde o típo de rabdomioma simples representado principalmente pelo rabdomioma congênito do coração até o típo de rabdomioma sarcomatóide (caso de Bradley e Maxwell). 
Merecem atenção os rabdomiomas congênitos do coração, não só devido à sua importância no grupo, como tambem por ter sido descrito um caso na literatura veterinária e pelas discussões surgidas quanto à sua significação.

Esses tumores costumam aparecer em fórma de nódulos múltiplos, com localização vária, às vezes sub-endocárdica, outras vezes na intimidade do miocárdio, ou ainda fazendo saliência no epicárdio. Pódem aparecer tambem solitáriamente e mesmo com pedículo. São tumores mais próprios da tenra idade, pois, ainda não foram observados na idade avançada. Vêm acompanhados quasi sempre, de anomalías em outros órgãos, tais como a esclerose cerebral, rim policístico, etc. A sua estrutura histológica é caracteristica, apresentando uma imagem muito bem descrita por WoLBACH, donde extraímos a seguinte descrição: "O tumor é fartamente composto de células com fibrilas estriadas, que, em algumas zonas, se apresentam com os detalhes completos das fibrilas normais.

Na maioria das vezes, são formadas por grânulos unidos por material fibrilar delicado. Os grânulos são corados profundamente pela hematoxilina férrica. Com hematoxilina e ácido fosfotungstico, os grânulos coram-se em azul intenso, as fibrilas em pardo-claro ou cinzento. Com a coloração de Mallory para o tecido conjuntivo, os grânulos coram-se em vermelho e a substância fibrilar em azul.

As células apresentam, pelo menos, estruturas em fórma de cachos de grânulos pares, tendo propriedades corantes dos centríolos, os quais estão incluidos ou conjugados no centroplasma ou centrolina. Os grânulos individuais (centríolos) médem mais ou menos 0,2 micron de diâmetro. Os corpos maiores são provavelmente amontôados de grânulos e raramente atingem 2 micra de diametro. Os diametros de 1 a 1,5 micron são frequentes, mas, a maioria apresenta de 0,5 a 1 micron.

Em escala de complexidade, aparecem primeiro as células com grandes massas de grânulos pares. Outras células apresentam algumas finas fibrilas, conjugando os grânulos e o começo de um arranjo ordenado para a formação de fibrilas segmentadas, correndo em todas as direções. Algumas contêm fibrilas com estriações transversais, grossas e finas. A maioria das fibrilas tem a aparência de grânulos enfiados em fibrilas, uniformemente colocados à distância de 1,6 micron $\mathrm{e}$ arranjadas em fila. Espalhados entre as fibrilas segmentadas, ha amontôados compostos de 2 ou vários centríolos, frequentemente em fórma diplóide. Esses amontôados de centríolos têm todos os caracteristicos dos das células diferenciadas e pódem ser interpretados como centríolos eliminados e dispérsos. 
As células tumorais variam de 50 a 200 micra de diâmetro e a maioria dos núcleos está colocada entre os limites de 9 e 7 micra e 13 e 10 micra».

Os rabdomiomas congênitos do coração apresentam as chamadas células em aranha, atrás descritas, células essas que fizeram com que os primeiros investigadores, principalmente KNOX e SHORER, as identificassem às fibrocélulas de Purkinje, existentes nos feixes de condução do miocárdio. Em favor dessa hipótese, estabeleciam as semelhanças existentes entre os dois típos de células. Mas, ao invés de os indivíduos portadores dêsses tumores apresentarem perturbações decorrentes do ritmo cardíaco, o que seria de prever, nada se verificou e a maioria dêles tinham o feixe de His íntegro e os nódulos tumorais se assestavam longe dêle.

Outros pesquisadores, entre os quais REHDER, ao verificarem a grande semelhança dessas células com as existentes em corações de animais inferiores (rã) e de féto humano, assim como a benignidade do tumor em questão, foram levados a considerar tal tumor, não no verdadeiro sentido de blastôma, um hamartoblastôma, mas, sim como um hamartôma, isto é, um tecido formado por células que permaneceram em estado embrionário. Em apoio maior dessa hipótese estaria a existência, nos indivíduos portadores dêsses tumores, de anomalias assestadas em outros órgãos, tais como a escleróse do cérebro, o rim policístico, a escleróse pancreática, etc., todas elas congênitas.

Mais recentemente, outros investigadores (REITANo e Nucciotti), estudando o bioquimismo das células do miocárdio, concluiram que tais tumores nada mais são que perturbações do crescimento normal das células, levando a uma hipernutrição com depósito de glicogênio e de gordura, diferenciando-se dos blastômas, por lhes faltarem outros atributos de uma célula neoplástica verdadeira.

Por todas essas razões, alguns anatomo-patologistas, procuraram contornar a questão, creando um lugar à parte, na classificação dos rabdomiomas e, para isso se basearam nessas particularidades consideradas como apanágio de tais tumores. Verificando-se, porém, que, em outras partes do organismo, particularmente na língua, apareciam rabdomiomas com estrutura semelhante à acima descrita e, apresentando, em alguns casos, caracteres de acentuada malignidade, somos levados a enfileirá-los ainda no grupo dos rabdomiomas atípicos, até que novos dados venham esclarecer a questão.

Nada de específico ou caracteristico notamos na sintomatologia clínica dos tumores do coração. Geralmente são achados de necroscopias. Nos casos em que foi dado apreciar a evolução da moléstia, 
os sintômas consistiam no aparecimento de uma insuficiência ventricular, acentuando-se progressivamente até a morte.

Pelo exame radiológico, póde aparecer um alargamento acentuado, não pulsátil, de um segmento cardíaco, levando à hipótese de uma infiltração blastomatósa. Foi o que verificou L. Popp em um caso de sarcoma localizado na aurícula direita, talvez o primeiro diagnosticado radiológicamente.

Com exceção do caso de Bradley e MAxwell de um rabdomiosarcoma que apresentou um elevado gráu de malignidade, levando à morte um indivíduo que, em toda a sua vida, tinha aparentado bom estado de saúde, quasi todos os rabdomiomas foram encontrados em individuos de tenra idade, não apresentando, no funcionamento cardíaco, fatos dignos de nota. No entretanto, verificou-se uma bôa porcentagem de indivíduos com perturbações psiquicas e nervosas, tais como atraso mental, idiotía, crises epilepticas, convulsões, etc., devído naturalmente às lesões cerebrais concomitantes.

O caso que apresentamos é do coração de um bovino abatido no Frigorífico da Companhia «Armour». O animal aparentava bom estado de saúde, nada se notando de anormal ao exame anterior.

O coração havia sido separado dos vasos da base por um plano passando pelo meio das aurículas, daí não conseguirmos uma observação mais detalhada dessas duas cavidades. Pesava 1,410 grâmas e media, no eixo longitudinal maior (da ponta à parte mais distal na base), 45 centimetros e, no maior eixo transversal, 42 centímetros de comprimento. Esse eixo estava bastante aumentado a custas do ventrículo direito que se apresentava muito dilatado. As cavidades cardíacas haviam sido abertas por córtes que não obedeciam às regras comumente empregadas na técnica de necroscopia. Ao afastarmos os lábios dos córtes efetuados na parêde do ventrículo direito, deparámos com um tumor de fórma globósa, ocupando quasi toda a cavidade ventricular. Era do tamanho da cabeça de féto humano e apresentava a sua superfície externa lisa, de côr vermelho-escura, com zonas circunscritas mais claras. O tumor além de ocupar a cavidade ventricular, forçava passagem pelo orifício aurículo-ventricular que se apresentava bastante dilatado, penetrando ligeiramente na aurícula direita. Era livre em toda a sua superfície e se inseria, por um pediculo grosso, no músculo papilar da parêde septal parecendo tomar origem nêsse músculo. A válvula tricúspide, com suas valvas impelidas para a parêde ventricular, não se fechava, mesmo porque estava parcialmente envolvida pela massa tumoral.

Foi praticado um córte longitudinal no tumor, separando-o em duas porções, conseguindo dêsse módo atingir o seu ponto de implan- 
tação. O córte sangrou abundantemente e a superfície mostrou o quadro seguinte: Do músculo papilar partia um tecido branco-amarelado, bastante denso, da largura mais ou menos de dois centímetros, que se expandia em todas as direções em fórma de léque. Esse tecido formava a maior parte do pedículo e suportava a massa tumoral, constituida por tecido vermelho-escuro, brilhante, com zonas necrosadas e outras francamente hemorrágicas, estando algumas delas infiltradas por sáis de cálcio. O tumor estava revestido por uma capsula delgada que se continuava com o endocárdio vizinho.

A parêde ventricular direita estava adelgaçada e bastante distendida ao contrário da parêde ventricular esquerda que se apresentava ligeiramente hipertrofiada.

Não foram encontrados outros nódulos tumorais quér superficiais quér profundos no miocárdio.

O exame da carcassa como o das outras vísceras não revelou qualquer anomalía ou processo patológico outro.

Exame microscópico: - Foram retirados fragmentos de várias partes do tumor, fixados em formól a $10 \%$ e corados pela Hematoxilina-eosina, Van Gieson, Mallory e Hematoxilina férrica de Heidenhain.

Os córtes apresentam imagem mais ou menos idêntica em todas as lâminas, mostrando ser o tumor constituido por um tecido altamente celular, com zonas francamente hemorrágicas, outras em necróse onde frequentemente ha depósitos de sáis de cálcio. Esse tecido está separado do miocárdio por uma estreita zona fibrosa, que penetra através das fibras musculares, dissociando-as. As fibras miocárdicas estão fragmentadas e degeneradas, havendo em alguns pontos, hialinização. Algumas fibras apresentam núcleos grandes, vesiculosos e arredondados, assemelhando-se bastante ao mioblasto jovem.

Ha formação de grande quantidade de vasos que penetram na massa tumoral, tornando-a assim, ricamente vascularizada. Nas zonas hemorrágicas, vê-se o extravasamento sanguineo se fazer nos interstícios do tecido neoplásico, dissociando fibrilas que se coram pela eosina.

Com maior aumento, verifica-se nas células constituintes do tumor, elevado gráu de polimorfismo, predominando, porém, o típo de células fusifórmes, muitas sendo monstruosas. O protoplasma córa-se intensamente pela eosina; pelo Mallory, assume uma coloração arroxeada que se evidencía da coloração azul-intenso tomada pelo tecido conjuntivo. Pelo Van Gieson, nota-se afinidade pelo ácido pícrico. Pela coloração com a hematoxilina férrica de Heidenhain, nota-se a presença, no protoplasma da maioria das células constituintes do tumor, de fibrilas longitudinais, correndo principalmente na perifería das células. Com 
grande aumento, verifica-se que as fibrilas são formadas por grânulos muito pequenos, estreitamente ligados uns aos outros, por substância cimentante. Os núcleos dessas células são predominantemente fusifórmes, com as extremidades rombas (em fórma de charuto), embóra haja grande variedade de fórmas e tamanhos, notando-se a presença tambem de núcleos arredondados, outros com reentrâncias, etc.. Algumas células, notaveis pelo seu tamanho, apresentam núcleos monstruosos e às vezes múltiplos. A cromatina nuclear está organizada em blócos que se dispõem irregularmente, apenas nas adjacências da membrana nuclear, ou formando um blóco único. As mitóses são raras. Os núcleos apresentam-se com vácuolos grandes e pequenos.

Resumindo, temos a notar o seguinte: 1.0 O tumor é constituido por células mioblásticas atípicas. 2. ${ }^{\circ}$ Com coloração apropriada, conseguiu-se a evidenciação das estriações, embóra imperfeitas. 3.० As células neoplásicas apresentam um elevado gráu de anaplasía. Tais elementos nos obrigam a classificar esse tumor como um Rabdomioblastôma, correspondendo ao típo que Abricossof e de CAPPEL e MontgoMERY denominaram «Rabdomioma sarcomatóide».

Não conseguimos, na literatura veterinária, identificação do nosso caso com os já conhecidos, pois pelas descrições apresentadas verificámos ser o caso de BousEK, um adeno-rabdomioma, com os caracteres próprios de um teratôma e o de Hyeronymi e KUKLA, um clássico rabdomioma congênito do coração. Do caso de MAGNisson, como dissémos atrás, não foi possivel obter maiores detalhes. Na literatura médica geral, um caso apenas se assemelha bastante ao quadro microscópico do nosso e é o de Bradley e Maxwell, aliás diagnosticado por Ewing, como sendo um rabdomiosarcoma, diferindo por se apresentar em fórma difusa, com metástases em outros órgãos, enquanto que o nosso era francamente polipóide e sem metástases.

Esse caso foi considerado como o primeiro dêsse típo aparecido na literatura mundial. Os outros rabdomiomas, em número de 45 até agora descritos, pertencem ao grupo dos rabdomiomas congênitos do coração e o quadro histológico é bem diferente do apresentado pelo nosso caso.

Assim, podemos dizer que o Rabdomioblastôma do coração é um tumor bastante raro e isso, quér se considere o fato de ser um neoplasma originário da musculatura estriada, quér sua localização em um órgão pouco sujeito a esse processo patológico, como é o coração.

\section{RESUMO}

Depois dos estudos de CARREL e seus continuadores sôbre as culturas «in vitro» de miocárdio de embrião de galinha e, principal- 
mente, dos trabalhos de ABricossof e outros, sôbre os miomas, os tumores originados da musculatura estriada têm sido classificados da seguinte maneira:

$10^{\circ}$ - Tumores cujas células apresentam estriação transversal bem definida.

a) Rabdomioma simples, formado inteiramente de fibras musculares bem diferenciadas e sem fórmas anaplásticas e primitivas.

b) Rabdomioma maligno ou rabdomioma sarcomatóide, sarcoma pleiomorfo, de células redondas e fusifórmes, apresentando estriação transversal bem definida, pelo menos num pequeno número de células. blastômas).

2. ${ }^{\circ}$ - Tumores cujas células não apresentam estriação (mio-

Poucos são os casos de rabdomioma observados em coração de animais e relatados; um dêles pertence ao grupo dos chamados rabdomiomas congênitos e ouïo é um adeno-rabdomioma (teratôma). Na literatura médica, com exceção de um rabdomiosarcoma (rabdomioma sarcomatóide), os outros pertencem ao grupo dos rabdomiomas congênitos.

O autor apresenta um caso de rabdomioma originado na musculatura cardíaca de um bovino. O tumor era pediculado e nascia no músculo papilar da parêde septal do ventrículo direito.

O exame microscópico revelou tratar-se de um tecido formado por células fusifórmes, de núcleo jovem e pela coloração especial (Hematoxilina férrica de Heidenhain), conseguiu-se evidenciar fibrilas formadas por pequenos grânulos juxtapostos, no protoplasma da maioria das células. Havia tambem um típo de células relativamente grande, com núcleos polimorfos e vacuolizados (megamiocitos de Houette).

Por esses achados, classificou-se o tumor em apreço como um rabdomioma maligno ou rabdomiona sarcomatóide, tumor rarissimo pois, quér na literatura geral, como nas inspecções de matadouro, não se conseguiu encontrar um caso semelhante, podendo apenas ser comparado com o de BRADLEY e MAXWELL.

\section{SUMMARY}

According to the studies of CARREL and his continuators with cultures «in vitro» of the miocard of fowl's embryo and expecially after the researches of ABRICOSSOF and others on the miomas, the tumors, originated in striated muscle have been classified as follows:

1st. - Tumors whose cells show a well defined transversal striation.

a) Simple rabdomioma, formed entirely be well defined muscular fibers and without anaplastic or primitive forms. 
b) Malign rabdomioma or sarcomatoid rabdomioma, pleiomorphic sa coma formed by round and fusiform cells, showing well defined transversal striation, at least in a small number of cells.

2d. - Tumors whose cells do not show striation (mioblastoma).

Veterinary literature records few cases of rabdomioma originated in the animal heart, one of them belonging to the group of the so-called congenital rabdomioma and another is an adenorabdomioma (teratoma). In the medical literature, except a rabdomiosarcoma (sarcomatoid rabdomioma), the others belong to the group of the congenital rabdomioma.

The author presents a case of a rabdomioma originated in the cardiac musculature of a bovine. The tumor was pedunculated and grew in the papilar muscle of the septal wall of the right ventricle.

The microscopic examination revealed a tissue formed by fusiform cells, with young nuclei, and with a special stain (Heidenhain's iron hematoxilin) it was possible to discover fibrils formed by small united granules, in the protoplasm of the majority of the cells. There was also a type of relatively large cells with polymorphic and vacuolated nuclei (Houette's megamiocites).

From these findings, the tumor in question was classified as a malign rabdomioma or sarcomatoid rabdomioma, consequently a very rare tumor, both in the general literature and in abattoir inspections.

It was not possible to find a similar case, it being only comparable to that described by BRADLEY and MAXWELL.

\section{BIBLIOGRAFIA}

ABricossof, A. I. - 1926 - Über Myome ausgehend von der guergestreiften willkürlichen muskulatur. Virchow's Arch. Path. Anat. u. Physiol. 260, (1) $215 / 36$.

Abricossof, A. I. - 1931 - Dalneïchïe issledovanïa rabdomiome iz mioblastoff. Voprossy Onkologuii. Kharkoff, 4, 21/34. Ref. in Index Analyticus Cancerologiae, 4, (1), 119, 1932.

Berger, L., Vallee, A. 1930 - Les rhabdomyomes congenitaux du coeur. Ann. Anat. Path. 7, (7), 797/811.

Bradley, E. B., Maxwell, E. S. - 1928 - Primary neoplasm of the heart. J. A. M. A. 91, 1352.

Cappel, Montgomery - 1937 - Rhabdomyoma and myoblastoma. J. Path. and Bact. 44, 517/48.

Courteau, R. - 1935 - Pathologie comparée des tumeurs chez les mamiféres domestiques. Paris, E. Le François.

DAvid, R. F. - 1932 - Contribution a l'etude des rhabdomyomes. Thése Facul. Med. Bourdeaux.

Distefano, G. - 1936 - Istogenesi e classazioni dei rabdomiomi benigni e maligni. Tumori, 15, (3), 293.

Eliakıs, M. - 1937 - Mort subite d'un nouveau-né par Rhabdomyome du coeur et reins polykistiques. Ann. Med. Leg. 17, 815/18. 
Ewing, J. - 1934 - Neoplastic diseases, 3nd edition, Philadelphia, W. B. Saunders.

FARber, S. - 1931 - Congenital Rhabdomyoma of heart. Am. Journ, Path. $7,105 / 50$.

Feldman, W. H. - 1932 - Neoplasms of domesticated animals. Philadelphia, W. B. Saunders.

Hueper, W. C. - 1935 - Rhabdomyomatosis of the heart in a negro. Arch. Path. 19, (3).

Hyeronymi, E., Kukla, R. - 1921 - Ein Beitrag zur kenntnis der angeborenen Rhabdomyome des Herzens. Virchow's Arch. Path. Anat. Physiol. 232, $459 / 79$.

MONTPELleR, J. - 1929 - Les rhabdomyomes. Caractères généraux et variétés anatomo-cliniques. Etude critique. Bull. du Cancer, 18, 538/602.

Morpurgo, B. - 1935 - Mioblastomi. Arch. Sc. Med. 59, (2).

MüLlER, W. - 1932 - Uber polipöse, bösartige, metastasierend Endocardgewäschse und gewärchartige Thromben des Linken Herzvorhofs. Virchow's Arch. Path. Anat. Physiol. 248, 105.

Peyron, A. - 1929 - Les tumeurs des muscles. Atlas du Cancer. Septiême Fascicule, Sept. Libraire Félix Alcan.

Roskin, G. - 1934 - La cellule myomateuse et quelques problemes relatifs à la cellule musculaire. Bull. du Cancer. 23, (2), 172/218.

TibiriçA, P. - 1932 - Acerca dos neoplasmas miomatosos - Ann. Fac. Med. de S. Paulo $-8,129 / 138$.

Wolbach, S. B. - $1928-$ Centrioles and the histogenesis of the myofibril in tumors of striated muscle origin. Anat. Res. 37, (3), 255/73, Ref. in Biological Abstrats, 3, (1-3), 177, 1929.

\section{EXPLICAÇÃO DAS ESTAMPAS}

Est. n.o 1 - Coração de bovino, aberto, deixando ver um tumor ocupando o ventrículo direito e parte da aurícula direita.

Est. n.०2-Coração de bovino com as paredes aurícular direita e ventricular direita fortemente rebatidas para mostrar a fórma globosa do tumor.

Est. n. $3-\mathrm{O}$ tumor cortado pelo meio e as duas partes separadas para mostrar a superfície de córte.

Est. n.० 4-Microfotografia de um córte histológico do tumor, em pequeno aumento, mostrando a tendência à formação de fibras.

Est. n. 5 - Microfotografia com maior aumento de um córte histológico corado especificamente (Hematoxilina férrica de Heidenhain), mostrando a formação de fibrilas no protoplasma das células.

Est. n.॰ 6 - Microfotografia, em grande aumento, de um córte histológico corado especificamente (Hematoxilina férrica de Heidenhain), mostrando a formação de miofibrilas no protoplasma das células pela juxtaposição de grânulos. 
R. E. Pires e P. Mucciolo, Rabd. no coraşâo de um bovino Rev. Fac. Med Vet. S. Paulo, Vol. 1, fasc. 2
Estampa 1

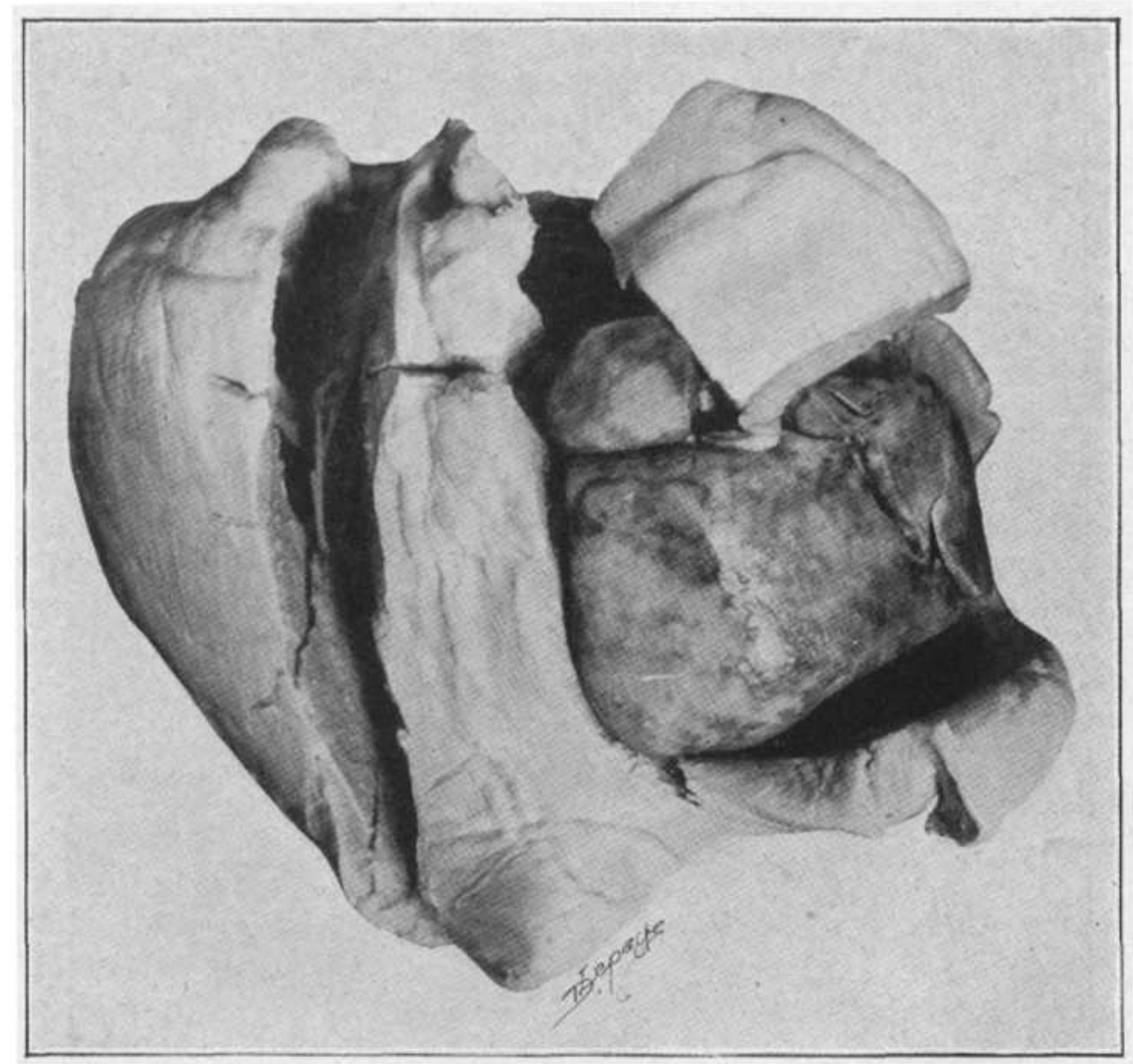


R. E. Pires e P. Mucciolo, Rabd. no coraçâo de um bovino Rev. Fac. Med. Vet. S. Patto, Vol. I, fasc. 2
Estampa 2

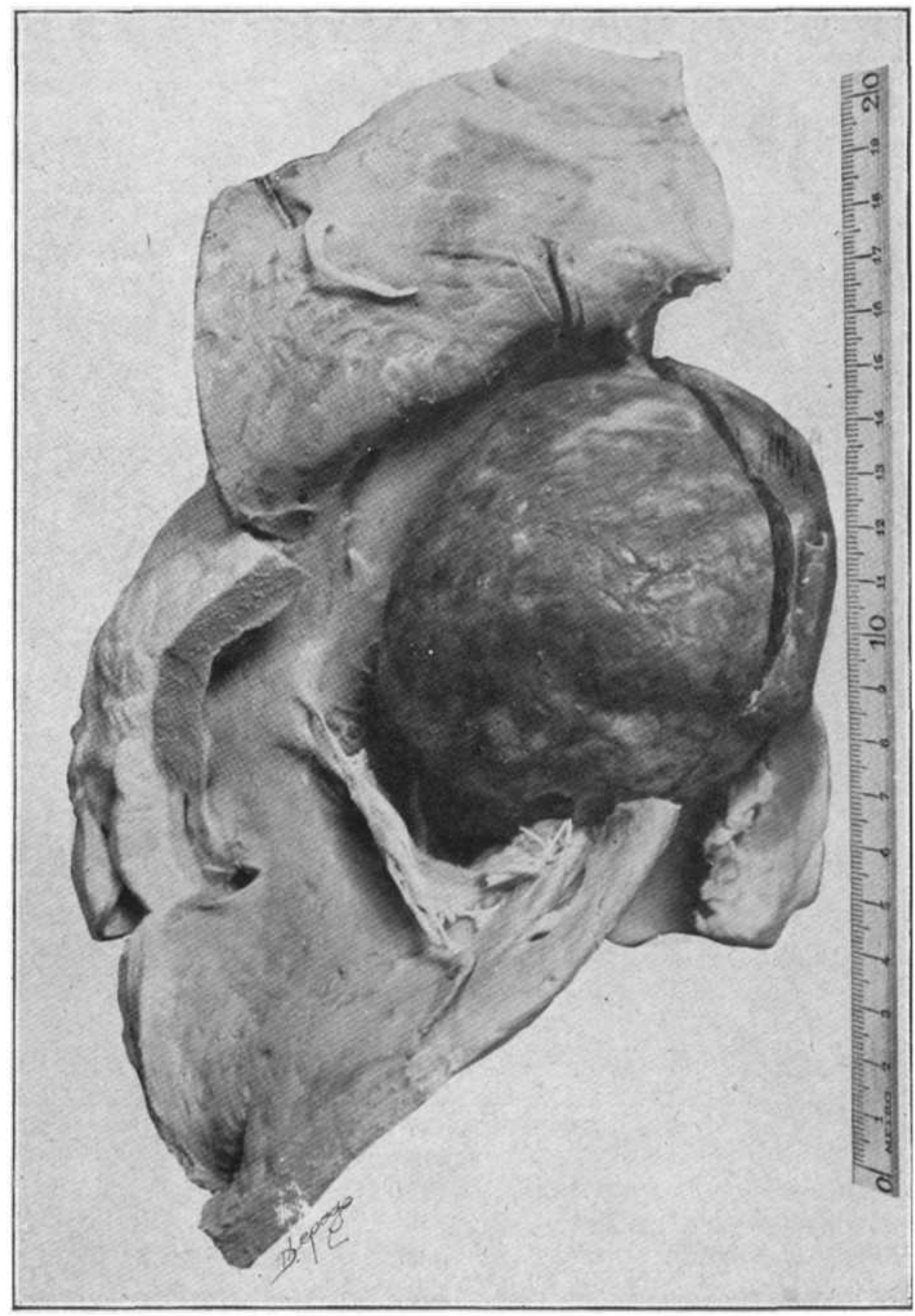


R. E. Pires e P. Mucciolo, Rabd. no coraçâo de um bovino Rev. Fac. Med. Vet. S. Paulo, Vol. I, fasc. 2

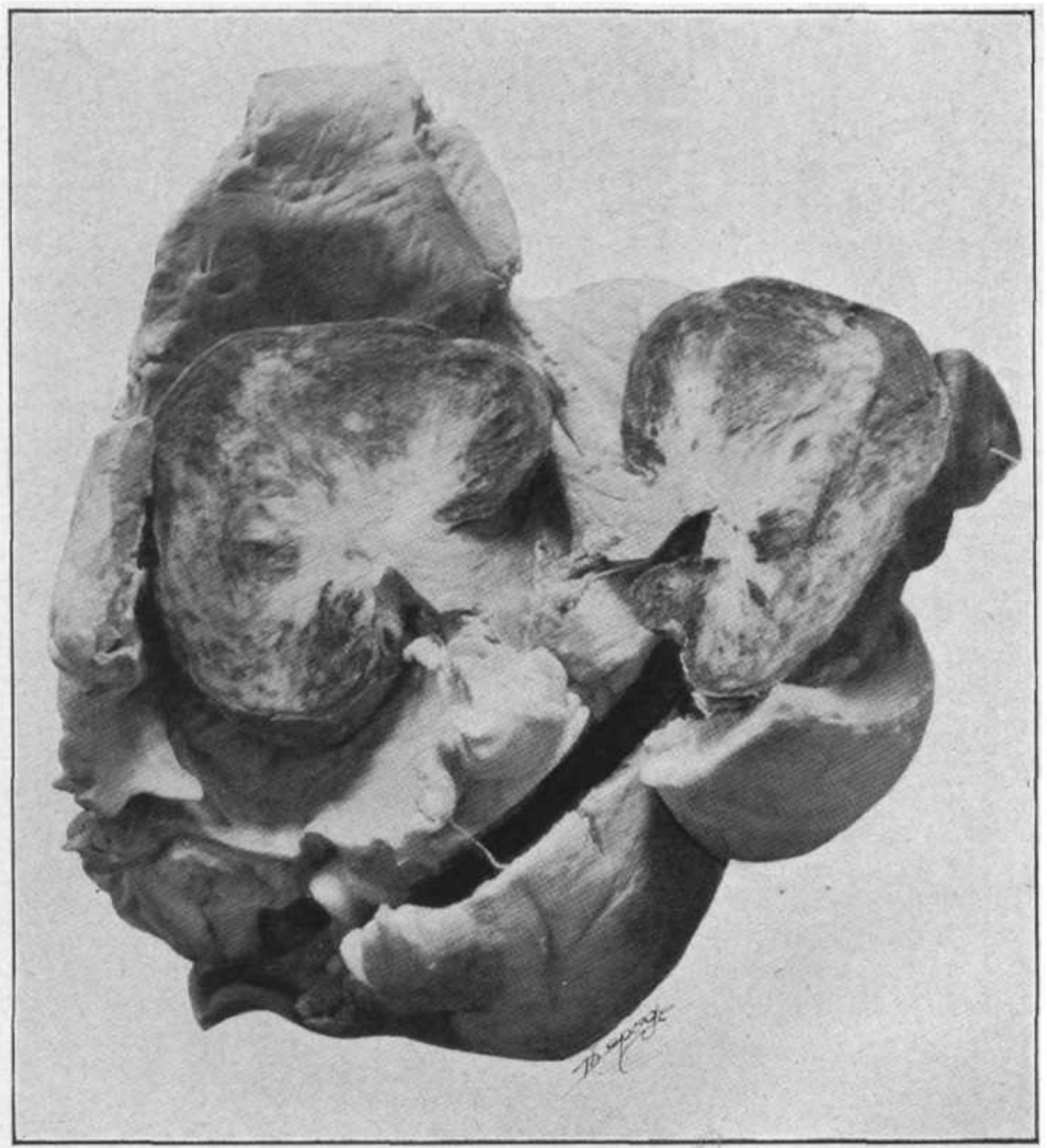




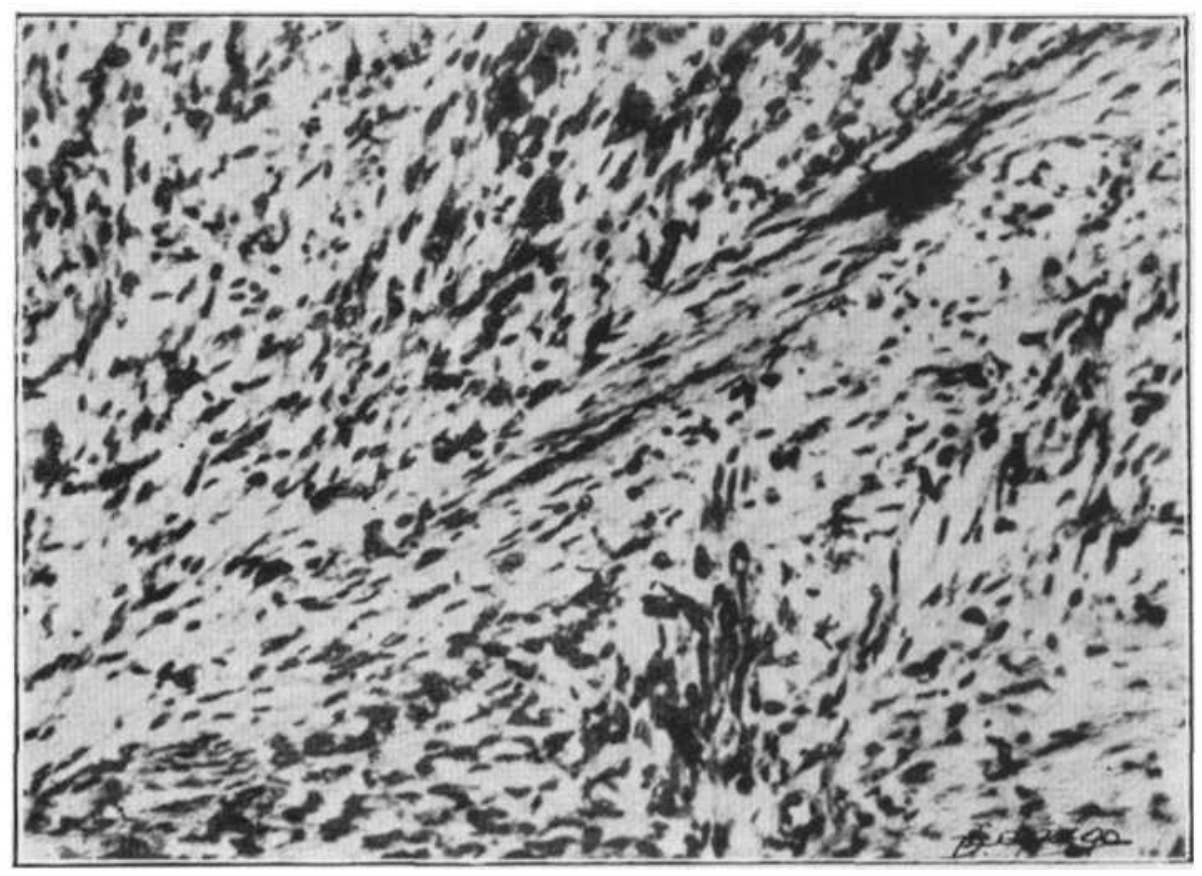


R. E. Pires e P. Mucciolo, Rabd. no coraçâo de um bovino Rev. Fac. Med. Vet. S. Paulo, Vol. I, fasc. 2

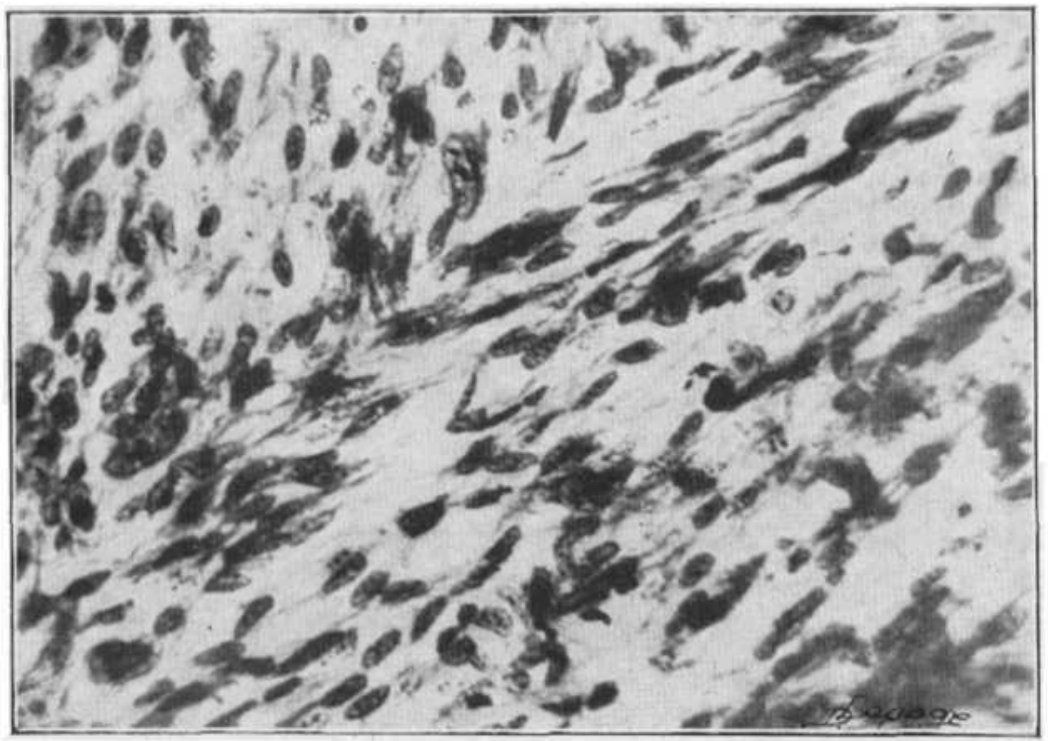

5

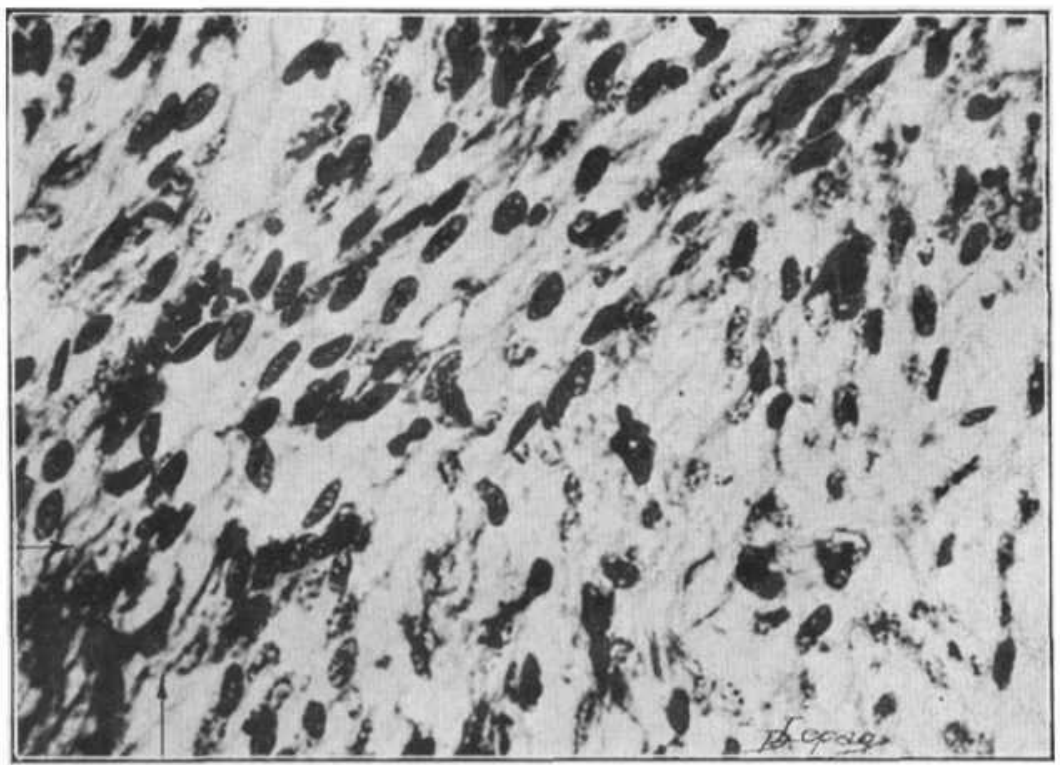

